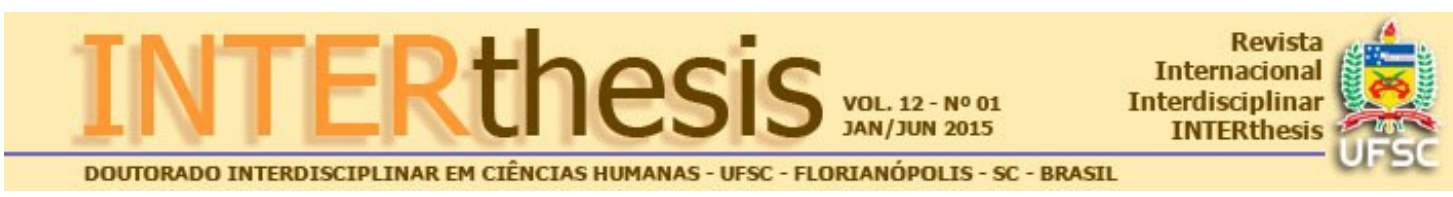

\title{
EXPERIMENTAÇÃO ANIMAL: UM COMBATE JURIDICO NAS UNIVERSIDADES BRASILEIRAS
}

\author{
Fernanda Luiza Fontoura de Medeiros ${ }^{1}$ \\ Letícia Albuquerque ${ }^{2}$
}

\section{Resumo:}

A vivissecção, ou o uso de animais em experimentos, testes ou educação faz parte de um contexto em que muitas pessoas ainda pensam representar um conflito de emergência que requer a escolha dos interesses humanos ao invés dos interesses dos animais. No Brasil, a Constituição Federal de 1988, em seu artigo 225, paragrafo $1^{\circ}$, inciso VII, veda a prática de crueldade com os animais. Para regulamentar o referido dispositivo, foi sancionada em 2008 a Lei 11.794/2008, conhecida como Lei Arouca, que estabelece procedimentos para o uso cientifico de animais e a Lei 9.605/2008, que versa sobre os crimes ambientais. Contudo, diante do que estabelece a Constituição é possível sustentar o uso de animais no ensino e na pesquisa, sobretudo nas universidades? O objetivo do presente artigo é analisar a legislação brasileira à respeito do uso de animais em testes, ensino e pesquisa e através das ações judiciais movidas nos últimos anos por entidades de defesa animal contra diversas universidades brasileiras discutir a aplicação da legislação referida, bem como demonstrar o embate jurídico e politico que o tema desperta. Os resultados apontam para um desacordo entre as práticas vigentes nas universidades, a legislação e o que dispõe o texto constitucional.

Palavras-chave: Direitos Animais. Vivissecção. Experimentação animal. Crueldade. Ação Civil Pública.

\section{INTRODUÇÃO}

A utilização dos animais não-humanos tanto na investigação científica quanto na atividade docente tem se apresentado como uma prática constante que acompanha a própria história da ciência (FEIJÓ, 2005, p. 13). No entanto, a referida prática nem sempre - para não dizer raramente - vem fundamentada em princípios éticos claramente definidos. Portanto, o uso de animais em testes, no ensino e na

\footnotetext{
${ }^{1}$ Doutora em Direito pelo Programa de Pós-Graduação em Direito da Universidade Federal de Santa Catarina. Professora da Faculdade de Direito da Pontifícia Universidade Católica do Rio Grande do Sul, Porto Alegre, RS e do Projeto de Mestrado em Direito e Sociedade da Faculdade de Direito do Centro Universitário La Salle, Canoas, RS, Brasil. E-mail: flfmedeiros@gmail.com

2 Doutora em Direito pelo Programa de Pós-Graduação em Direito da Universidade Federal de Santa Catarina, com estágio de Doutoramento na Faculdade de Direito de Coimbra/Portugal, bolsista CAPES. Professora dos cursos de Graduação e Pós-graduação em Direito da Universidade Federal de Santa Catarina, Florianópolis, SC, Brasil. E-mail: leticia.albuquerque@ufsc.br
}

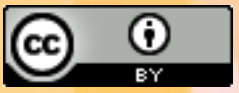

Esta obra foi licenciada com uma Licença Creative Commons - Atribuição 3.0 Não Adaptada. 
pesquisa é uma questão controversa. Singer desde a publicação de seu livro Libertação Animal (SINGER, 2002), apontava o uso de animais em experimentos como uma das formas mais evidente de especismo, uma vez que aqueles que realizam tais experiências, bem como aqueles que concordam com tal prática, sempre tentam justificar a sua realização com o argumento de que as experiências nos levam a descobertas sobre os seres humanos (2002, p.75). Para o autor, os especistas atribuem maior peso aos interesses dos membros de sua própria espécie: "os especistas humanos não admitem que a dor é tão má quando sentida por porcos ou ratos como quando são os seres humanos que a sentem" (SINGER, 2002, p.68).

Passados quarenta anos da publicação da obra de Singer, a polêmica continua. Conforme Francione (2013), se hoje o uso de animais para fins de entretenimento, alimentação, vestuário ou outros usos ligados ao nosso prazer, diversão ou conveniência não podem ser considerados necessários em nenhum sentido uma vez que temos uma obrigação direta com os animais de não Ihes infligir sofrimento, tal ponto de vista não é amplamente compartilhado com relação a prática da vivissecção. A vivissecção, ou o uso de animais em experimentos, testes ou educação faz parte de um contexto em que muitas pessoas ainda pensam representar um conflito de emergência que requer a escolha dos interesses humanos ao invés dos interesses dos animais.

Aqueles que se opõem a utilização dos animais não-humanos como objeto da vivissecção, seja para a pesquisa científica, seja para a atividade docente, se apoiam, regra geral, em duas questões: uma ética e a outra científica. Brügger (2008, p. 146) destaca na questão ética "ao direito que temos de dispor da vida de seres sencientes [...] causando-lhes sofrimento físico e psicológico e interrompendo suas vidas". A autora, ressalta, ainda, que a razão de ordem científica "diz respeito à falta de confiabilidade dos dados provenientes de experimentos com animais nãohumanos". Medeiros (2013, p. 225) alerta que o "uso de animais não humanos como colaboradores não voluntários das pesquisas científicas data de milhares de anos" e destaca que:

[...] o conhecimento acerca dos processos biológicos e todas as interações para a manutenção e desenvolvimento da vida estão crescendo em proporção sem precedente [...] despertando uma preocupação entre os cientistas e a comunidade em geral sobre a segurança no uso de todas 
essas tecnologias e os efeitos que possam ter sobre a dignidade dos homens e dos animais.

Discussão que, nitidamente, não se apresenta de forma tranquila. Levai (2004) alerta que toda e qualquer prática que utiliza animais para fins didáticos ou de pesquisa é, no mínimo, bastante controversa. No Brasil, a questão da utilização dos animais não-humanos como objetos de pesquisa e meios para docência já se havia regulado por meio da Lei de Vivissecção, a Lei n. ${ }^{\circ}$ 6.638/79. Com o advento da nova ordem jurídico-constitucional no país, se observou uma virada significativa no que concerne aos animais.

A Constituição Federal de 1988 , em seu artigo 225 , paragrafo $1^{\circ}$, inciso VII, veda a prática de crueldade para com os animais não-humanos. Em face da mudança constitucional, uma nova norma veio para regulamentar o referido dispositivo, foi sancionada, portanto, em 2008 a Lei n. ${ }^{\circ}$ 11.794/2008, conhecida como Lei Arouca, que estabelece procedimentos para o uso científico de animais e a Lei 9.605/1998, que versa sobre os crimes ambientais. Contudo, diante do que estabelece a Constituição é possível sustentar o uso de animais no ensino e na pesquisa, sobretudo nas universidades? O objetivo do presente artigo é analisar a legislação brasileira a respeito do uso de animais em testes, ensino e pesquisa e através das ações judiciais movidas nos últimos anos por entidades de defesa animal contra diversas universidades brasileiras discutir a aplicação da legislação referida, bem como demonstrar o embate jurídico e político que o tema desperta. Os resultados apontam para um desacordo entre as práticas vigentes nas universidades, a legislação e o que dispõe o texto constitucional. Para tanto, serão analisadas três Ações Civis Públicas (ACPs), a título exemplificativo, propostas recentemente, uma envolvendo a Universidade Federal de Santa Catarina (UFSC), a Universidade Federal de Santa Maria (UFSM) e a Universidade Estadual de Maringá (UEM), o que representa uma amostra da região sul do país.

\section{EXPERIMENTAÇÃO ANIMAL E A LEGISLAÇÃO BRASILEIRA}

A Constituição Federal de 1988 introduziu uma nova forma de pensar a relação seres humanos-natureza ao elevar o direito ao meio ambiente ecologicamente equilibrado à categoria de direito fundamental. Essa alteração é 
uma mudança significativa, uma virada de Copérnico no âmbito da proteção ambiental. Silva (2002) defende que somente a consagração de um direito fundamental ao ambiente pode garantir a adequada defesa contra agressões ilegais, provenientes quer de entidades públicas, quer de privadas, na esfera individual protegida pelas normas constitucionais. Na mesma esteira, Medeiros assevera que "toda a matéria relacionada, direta ou indiretamente, com a proteção do ambiente, projeta-se no domínio dos direitos fundamentais" (2004, p. 114).

Medeiros ressalta, ainda, que tal vinculação ocorre, não somente pela inserção sistemática do meio ambiente no âmbito dos direitos fundamentais, mas também, por ser o Estado Democrático de Direito, um Estado Socioambiental Democrático de Direito, a garantia, a promoção e a efetivação desses direitos, uma vez que "o direito à proteção ambiental é um legitimo direito fundamental, uma vez que diz diretamente com a própria dignidade da vida" (MEDEIROS, 2004, p. 114). Portanto, a proteção ao ambiente é reconhecida como direito - e como dever fundamental na ordem jurídico-constitucional brasileira, tanto pela doutrina quanto pela jurisprudência. Nessa linha, Herman Benjamin aponta que a Constituição Federal de 88 assumiu um compromisso ético com a vida do Planeta em todas as suas formas, ao afirmar que:

\begin{abstract}
[...] nota-se um compromisso ético de não empobrecer a Terra e sua biodiversidade, com isso almejando-se manter as opções das futuras gerações e garantir a própria sobrevivência das espécies e de seu habitat. Fala-se em equilíbrio ecológico, instituem-se unidades de conservação, combate-se a poluição, protege-se a integridade dos biomas e ecossistemas, reconhece-se o dever de recuperar o meio ambiente degradado - tudo isso com o intuito de assegurar no amanhã um Planeta em que se mantenham e se ampliem, quantitativa e qualitativamente, as condições que propiciam a vida em todas suas formas.
\end{abstract}

O Capítulo dedicado ao meio ambiente, composto pelo artigo 225 , parágrafos e incisos, segundo o referido autor é um dos mais modernos e marca a saída do estágio da "miserabilidade ecológica constitucional" para o que chama de "opulência ecológica constitucional" (BENJAMIN, 2008, p.8). Assim como marca o abandono do antropocentrismo radical para um olhar que ultrapassa, em parte, inclusive o antropocentrismo moderado, ao proteger, entre outras referências, os animais de atos de crueldade, demonstrando uma imersão - mesmo que ainda tímida - na esfera do sensocentrismo.

No entanto, essa "opulência ecológica constitucional" ainda, grosso modo, 
percebe os animais como função ecológica e não como seres sensíveis e sujeitos de uma vida, apesar do próprio texto constitucional permitir um novo olhar a respeito da questão animal ao vedar a crueldade no art.225, paragrafo $1^{\circ}$, inciso VII. Tal dispositivo tem sido utilizado por vários movimentos de defesa animal e direitos animais como instrumento para através de ações judicias provocar uma mudança na relação entre animais humanos e não humanos. A mudança torna-se possível e facilita a argumentação jurídica, haja vista que o inciso VII, do parágrafo $1^{\circ}$, do artigo 225 muito extrapolou o antropocentrismo moderado defendido pelo sistema jurídico pátrio, o texto constitucional, abre-se para um novo olhar, um olhar não sistêmico, um olhar pelo indivíduo e não pela sua função ecológica ou social, como se pode constatar por meio da transcrição infra:

Art. $225[\ldots]$

$\S 1^{\circ} .[\ldots]$

VII - proteger a fauna e a flora, vedadas, na forma da lei, as práticas que coloquem em risco sua função ecológica, provoquem a extinção de espécies ou submetam os animais a crueldade.

A discussão da experimentação animal tanto no ensino quanto na pesquisa, passa por tal dispositivo. E, nesse sentido e a partir dessa proposição constitucional surge o questionamento: ora, se a Constituição Federal veda a crueldade, como sustentar a prática da vivissecção/experimentação animal?

Ainda em momento anterior à Constituição de 1988, havia uma legislação que regulamentava a exploração dos animais não-humanos nos laboratórios de pesquisa e nos bancos acadêmicos, conhecida como Lei da Vivissecção. Certo afirmar, em tempo, que tal regulação estava calcada em norma constitucional anterior a virada de 1988. Medeiros destaca que a Lei n. ${ }^{\circ} 6.638 / 79$ era uma legislação

[...] que ainda causava polêmica nos bancos acadêmicos, em razão dos múltiplos questionamentos que comportava, em face da carência de uma abordagem ética e bioética que há pouco vem despertando e, em razão dos avanços tecnológicos a que se está subjugado, é a lei que regula a vivissecção de animais para a pesquisa científica e para fins didáticos. A lei regulamentava a prática em todo o território nacional desde que os biotérios e os centros de experiências e demonstrações com animais vivos estivessem registrados.

Mesmo que altamente questionável, a Lei $n .^{\circ} 6.638 / 79$ apontava um pequeno lampejo de caráter protetivo ao proibir a realização da atividade sem emprego de anestesia ou sem supervisão de um técnico especializado, conforme determinava o artigo $3^{\circ}$ e seus incisos. Ainda, a Lei $n .^{\circ}$ 6.638/79, apesar das criticas quanto a abordagem ética, não permitia a realização da experimentação animal em R. Inter. Interdisc. INTERthesis, Florianópolis, v.12, n.1, p.65-83, Jan-Jun. 2015 
estabelecimentos de ensino de primeiro e segundo graus, bem como em locais frequentados por menores.

Em 12 de fevereiro de 1998 adveio a Lei $n .^{\circ}$ 9.605, conhecida com a Lei dos Crimes Ambientais (LCA) ou Lei da Vida, já a luz da Constituição de 1988. A referida legislação dedicou um capítulo inteiro aos crimes cometidos contra a fauna. Conforme Medeiros:

[...] são nove artigos dedicados à proteção dos animais não-humanos, em sua maioria voltados para a proteção das espécies silvestres da fauna. Contudo, cumpre ressaltar que a partir da Lei n. ${ }^{\circ}$ 9.605/98, as atividades danosas cometidas contra a fauna passaram de contravenção para crime, o que para aqueles que buscam a proteção dos animais é uma gigantesca vitória (2013, p. 59).

O artigo 32 da Lei dos Crimes Ambientais, a Lei n. ${ }^{\circ}$ 9.605/98, na esteira do comando constitucional, proíbe a prática de ato abusivo, de maus tratos, de ferir ou mutilar animais silvestres, domésticos ou domesticados, nativos ou exóticos. Contudo, Medeiros argumenta que "caso ocorra o crime, a pena é de detenção de três meses a um ano, e multa, o que, de fato, é irrisório" (MEDEIROS, 2013, p. 60). Corroborando o mandamento da Constituição, o parágrafo $1^{\circ}$, do artigo 32 da Lei n. ${ }^{\circ}$ 9.605/98 aponta que incorrerá nas mesmas penas quem realiza experiência dolorosa ou cruel em animal vivo, ainda que para fins didáticos ou científicos, quando existirem recursos alternativos. Dispositivo que "parece ser ignorado quando se verifica a existência de uma outra norma (dentro do mesmo ordenamento jurídico) que disciplina a vivissecção, como o caso da Lei Arouca, uma lei insciente" (MEDEIROS, 2013, p. 61). A lei dos crimes ambientais, portanto, determina que:

Art. 32. Praticar ato de abuso, maus-tratos, ferir ou mutilar animais silvestres, domésticos ou domesticados, nativos ou exóticos:

Pena - detenção, de três meses a um ano, e multa.

$\S 1^{\circ}$ Incorre nas mesmas penas quem realiza experiência dolorosa ou cruel em animal vivo, ainda que para fins didáticos ou científicos, quando existirem recursos alternativos. (grifo nosso)

Atualmente a lei que regula a questão é a Lei $n .^{\circ} 11.794 / 2008$, conhecida como Lei Arouca. A Lei Arouca foi sancionada em 8 de outubro de 2008, revogando a legislação anterior que tratava do tema, a Lei n. ${ }^{\circ} 6.638 / 1979$. Nesse sentido Albuquerque e Medeiros (2014, p.330) afirmam que:

A Lei Arouca permite, conforme dispõe o inciso II, do $\S 1^{\circ}$, do art. $1^{\circ}$ que é possível realizar a vivissecção em estabelecimentos de educação profissional técnica de nível médio na área biomédica. É translucida a retrogradarão ambiental, ou como já se anunciou o retrocesso legislativo.

R. Inter. Interdisc. INTERthesis, Florianópolis, v.12, n.1, p.65-83, Jan-Jun. 2015 
Medeiros destaca que a Lei Arouca instaurou um "processo de retrocesso socioambiental jamais visto - até o ano de 2008 - no que concerne a proteção da fauna" (2013, p. 56). Segundo a referida autora (MEDEIROS, 2013, p. 56),

Constrói-se a figura da instauração da quebra do princípio de proibição de retrocesso, pois a Constituição Federal de 88, proibindo o tratamento cruel para com os animais não-humanos, já está encaminhando a legislação para um novo paradigma que foi ignorado pela Lei Arouca (Lei n. ${ }^{\circ} 11.794$, de 08 de outubro de 2008)

Além disso, surge a seguinte indagação: Como pode uma lei que regulamenta o uso de animais na pesquisa e no ensino, ou seja a exploração animal, estar de acordo com a CF88, que expressamente veda a crueldade animal? A Lei Arouca atende ao proposto pela Constituição Federal ou apenas reforça o status quo de exploração animal? (ALBUQUERQUE, MEDEIROS, 2014, p.26). Para as autoras referidas (ALBUQUERQUE, MEDEIROS, 2014, p.29),

A Lei Arouca nasce com a bandeira de proteção dos animais, nasce com a tarefa de regular a pesquisa com animais não-humanos no Brasil a partir da Constituição. Contudo, em uma análise prima facie, essa proteção não acontece. Observa-se a criação de mais biotérios, de mais centros de pesquisa, de CEUAs não capacitados, de representações não democráticas e de controle do poder a partir do controle do saber cientifico. A partir de um primeiro olhar, destaca- se a falácia e não a efetiva proteção.

Os questionamentos a respeito da constitucionalidade da Lei estão presentes desde a sua entrada em vigor. Para os juristas que atuam na defesa animal, a Lei Arouca, é considerada inconstitucional, justamente em razão da vedação da crueldade para com os animais e, portanto, a sua aplicação nos laboratórios de pesquisa (privados ou públicos) e nas salas de aula dos cursos biomédicos tem ensejado a propositura de Ações Civis Públicas questionando o uso de animais na pesquisa e, sobretudo, na docência, cujos métodos alternativos são bastante desenvolvidos e conhecidos.

\section{O USO DE ANIMAIS NAS UNIVERSIDADES}

Em outubro de 2011 a $13^{\mathrm{a}}$ Promotoria de Justiça da Comarca de Maringá proteção ao ambiente, fundações e terceiro setor - ajuizou uma ação civil pública ambiental contra a Universidade Estadual de Maringá (UEM). Os fatos que moveram a ação estavam presentes no Inquérito Civil n. ${ }^{\circ}$ MPPR n. ${ }^{\circ}$ 0088.10.000351-1 a partir de uma denúncia e de um abaixo assinado com mais de seis mil (6.000) assinaturas 
noticiando possível prática de maus tratos a cães da raça beagle no biotério da Universidade Estadual de Maringá e utilizados em experimentos científicos realizados por Departamento específico da referida instituição.

O Ministério Público do Paraná optou pelo pedido de proibição do uso de animais para experimentos e procedimentos clínicos no Curso de Odontologia da Universidade Estadual de Maringá. Foi constatado que os cães da raça beagle, utilizados nos procedimentos, eram submetidos a condições de maus-tratos, viviam em locais sem higiene e sofriam overdose com altas taxas de anestésicos. Todas as irregularidades foram confirmadas por laudo do Conselho Regional de Medicina Veterinária feito a pedido do Ministério Público. O pedido do parquet está centrado em obrigações de não fazer:

1.Abster-se a ré, responsável pelo departamento de odontologia, ainda que sob qualquer outra sigla, nome, de utilizar cães ou quaisquer outros animais em procedimentos experimentais no referido departamento, que Ihes causem lesões físicas, dor, sofrimento ou morte, ainda que anestesiados, seja em 2011 ou nos anos vindouros.

2. Abster-se a ré de criar cães de qualquer raça ou sem raça identificada ou de apanhá-los e mantê-los com a sua liberdade cerceada em seu Biotério Central, que se apresentou absolutamente inadequado para o bem-estar animal.

Pugna-se, ainda, pela FIXAÇÃO DE MULTA DIÁRIA com correção monetária pelos índices oficiais, na hipótese de eventual descumprimento da referida obrigação de não fazer (artigos 11 da Lei 7.347/85 e artigos 632 e seguintes, e 642/643 do Código de Processo Civil), no valor de R\$ $10.000,00$ (dez mil reais) por dia, ou, então, outro valor que Vossa Excelência considere mais apropriado (grifo nosso)

A ACP tramitando na $5^{\text {a }}$ Vara Cível de Maringá, sob o n. ${ }^{\circ}$ 25.709/2011, suspendeu as pesquisas com animais pelo curso de Odontologia. Em decisão fundamentada, o juiz da causa - Siladelfo Rodrigues da Silva - assim analisou:

O legislador pátrio, ao editar a Lei n. ${ }^{\circ} 11.794 / 08$, possibilitou que pesquisadores pudessem realizar experimentos científicos em animais desde que não haja outro meio alternativo capaz de obtenção dos mesmos ou melhores resultados com a pesquisa almejada. Esta é a finalidade da norma, até mesmo porque não se apresenta como lógica a utilização de animai s em pesquisas quando os resultados destas poder iam ser alvo de aferição por outro método que não constituísse risco à saúde e integridade física de um ser vivo. Porém, ao menos neste momento processual, denota- se que o referido preceito não vem sendo observado neste caso, haja vista que a documentação carreada ao feito, salvo melhor juízo, demonstra que as pesquisas científicas realizadas pela ré já estão sendo empregada em humanos, circunstância esta que afasta a conotação de necessidade de utilização de animai s (no caso cães) para tal fim. (grifo nosso)

Em decisão posterior, uma decisão judicial determinou a retirada dos cães que permaneciam no Biotério Central da Universidade Estadual de Maringá. Os cães

R. Inter. Interdisc. INTERthesis, Florianópolis, v.12, n.1, p.65-83, Jan-Jun. 2015 
foram encaminhados a Associação Anjos Animais. A UEM recorreu da decisão por meio de um agravo de instrumento de $\mathrm{n} .{ }^{\circ} 862610-8$ tendo sido negado o provimento.

Em abril de 2013, o Instituto Abolicionista Animal, entidade da sociedade civil, propôs ACP em face da Universidade Federal de Santa Catarina (UFSC) questionando o uso de animais no ensino em razão do descumprimento da legislação pertinente citada anteriormente: art.225, VII CF88; art.32, §1 $1^{\circ}$ da Lei dos Crimes Ambientais; art.5 $5^{\circ}$, III da Lei Arouca. A pretensão requerida ficou centrada no direito animal ao tratamento livre de crueldade ${ }^{3}$.

Outro ponto levantado foi quanto à competência do CONCEA de monitorar e avaliar a introdução de técnicas alternativas que substituam a utilização de animais em ensino e pesquisa. Assim, o argumento usado pelo IAA sustenta que a regra geral seria: quando houver métodos substitutivos o uso de animais torna-se crime. Para tanto, foram salientados os pontos da legislação vigente comentados anteriormente, principalmente $\mathrm{o}$ aspecto constitucional que muda a visão instrumental que tínhamos dos animais e passa a reconhecer o seu valor intrínseco ao vedar as práticas de crueldade.

Por outro lado, a UFSC, na sua contestação alega que: a) haveria violação da ordem e saúde públicas, em razão do prejuízo aos acadêmicos e ao ensino, caso a universidade deixasse de utilizar animais nas suas práticas; b) que houve a redução do número de animais utilizados, uma vez que há 2 anos a universidade não utiliza mais cães; c) quanto ao uso de animais na pesquisa, alega que os animais utilizados não pertencem à fauna brasileira e são criados para este fim. Ainda, em relação ao uso de animais na pesquisa, a direção do Centro de Ciências da Saúde, em manifestação do Professor Dr. Sergio Fernandes Torres de Freitas, no processo, alega que:

\begin{abstract}
Ha unanimidade de que sua utilização é necessária e fundamental para o desenvolvimento cientifico e deve ser mantida rotineiramente, considerando que sua suspensão provocaria grave prejuízo à ciência e à saúde publica. Não é demais confirmar que todas as pesquisas que utilizam animais na UFSC respeitam as normas internacionais de respeito ético, como pode ser atestado pela CEUA e por diversas publicações internacionais que exigem esse respeito ético para divulgação de resultados de pesquisa sob a forma de artigos científicos.
\end{abstract}

\footnotetext{
${ }^{3}$ Os aspectos levantados quanto ao caso da UFSC foram abordados em trabalho apresentado no Congresso de sociologia jurídica - Sociology of Law on the Move: perspectives from Latin America, realizado na UNILASALLE, Canoas, RS: ALBUQUERQUE, Leticia. SPECK, Rafael. O uso de animais no ensino e na pesquisa: o caso da Universidade Federal de Santa Catarina.
}

R. Inter. Interdisc. INTERthesis, Florianópolis, v.12, n.1, p.65-83, Jan-Jun. 2015 
A Universidade também alega que a utilização dos animais é feita sempre com todos os cuidados para que não haja sofrimento e de maneira a diminuir ao mínimo o stress a que serão submetidos através de técnicas adequadas. Aponta a impossibilidade de reproduzir em manequins algumas práticas cirúrgicas, como sangramento e os cuidados necessários quando se tem uma vida sob sua responsabilidade, impedindo o gerenciamento do stress pelo futuro médico.

Os argumentos da Universidade parecem desconsiderar a realidade de diversos cursos de excelência tanto no Brasil, como no exterior que utilizam métodos alternativos e aboliram totalmente o uso de animais, como por exemplo a Faculdade de Medicina, da UFRGS.

Outro argumento, alegado pela UFSC, que parece não ter sustentação, seria o alto custo para aquisição de tais métodos alternativos e a manutenção e reparação dos equipamentos. Todo esse investimento representaria um alto custo para um país com uma população ainda tão pobre. O que parece não ter justificativa é o alto custo para a manutenção de biotérios que sustentam práticas cruéis e degradantes tanto para os alunos quanto para os animais utilizados.

A UFSC alegou que as pesquisas em animais também se justificariam em razão da dependência de tecnologia estrangeira para a introdução de novos fármacos e terapias no SUS brasileiro e que a sua paralisação representaria perda de soberania nacional pela dependência internacional na área de medicamentos e perda de soberania nas decisões sobre a saúde do cidadão, patente, normativas nacionais e internacionais. No caso da ACP envolvendo a UFSC, o juiz ao examinar a questão de acordo com a legislação vigente considerou que (ACP $n^{\circ}$ 500968486.2013.404.7200/JFSC):

O Estado tem a obrigação de preservar o meio ambiente e os animais são parte indissociável do meio ambiente.

A preservação do meio ambiente constitui justificativa inclusive para a obtenção de recursos em caráter emergencial, a fim de suprir a falha da administração publica, que não adquiriu as matérias indispensáveis para o correto ensino da medicina.

Tais argumentos falaciosos apenas levam à conclusão de que as praticas cruéis devam ser cessadas e que os profissionais que utilizam tais expedientes devam fazer um exame de consciência.

Assim, em primeira instância a ACP foi julgada parcialmente procedente, conforme a decisão que segue (ACP $n^{\circ} 500968486.2013 .404 .7200 / J F S C$ ):

Julgo parcialmente procedente o pedido da autora para determinar que a ré, responsável pelo departamento de Medicina, se abstenha de utilizar cães

R. Inter. Interdisc. INTERthesis, Florianópolis, v.12, n.1, p.65-83, Jan-Jun. 2015 
ou quaisquer outros animais em aulas didáticas, técnicas cirúrgicas ou procedimentos experimentais no referido departamento, concedendo o prazo de 90 dias para que a Universidade adquira os equipamentos necessários. Até o dia 02 de outubro de 2013 a Universidade poderá usar apenas ratos e com anestesia para o ensino da Medicina, devendo após tal data abolir por completo qualquer utilização de animais, sob pena de aplicação de multa de $\mathrm{R} \$ 5.000,00$ (cinco mil reais) para cada animal utilizado.

A UFSC recorreu da decisão, pleiteando a suspensão da execução da sentença, em 4 de outubro de 2013 (Pedido de suspensão de execução de sentença $\mathrm{n}^{\circ} 50233381220134040000$ TRF4), a qual foi deferida pelo TRF em 9 de outubro de 2013, acatando os argumentos da Universidade:

Estabelecidas essas premissas, é possível que a imediata proibição de a Universidade utilizar quaisquer animais em suas atividades de pesquisa venha a acarretar prejuízos concretos à formação acadêmica dos futuros médicos, tais como o mencionado pelo Departamento de Cirurgia de Medicina da UFSC, no que se refere à impossibilidade de se reproduzir em manequins situações da pratica cirúrgica, a exemplo do sangramento e 'os cuidados necessários quando se tem uma vida sob sua responsabilidade, gerando um gerenciamento do stress ao futuro médico semelhante ao que estará sujeito quando tratar com seres humanos [...]'. Tal consequência, no meu sentir, expõe o interesse público da coletividade à ameaça de lesão. (...) afete uma série de projetos científicos em andamento, conforme demonstrado em levantamento realizado junto aos grupos de pesquisa da UFSC cujos projetos envolvem animais de experimentação -a maioria, financiados com recursos públicos-, de modo a ocasionar inegável prejuízo econômico àquela Universidade Federal.

Atualmente, o processo encontra-se ainda no TRF para julgamento da apelação e a informação que consta é que em 13 de março de 2015 o MPF manifestou-se pedindo o imediato prosseguimento do feito em razão da demora.

No mesmo ano, em julho de 2013, o Movimento Gaúcho de Defesa Animal MGDA - ajuizou Ação Civil Pública contra a Universidade Federal de Santa Maria UFSM. O pedido da associação autoria consistia em obstar a utilização de animais vivos para fins pedagógicos em aulas práticas dos cursos da UFSM. No relatório da decisão liminar na ACP de n. ${ }^{\circ}$ 5004455-51.2013.404.7102/RS, restou exposto que:

A Associação autora relata, em síntese, que o uso de animais vivos e saudáveis como recurso pedagógico pela universidade demandada configura maus tratos, confrontando normas de conduta ética e moral, especialmente em procedimentos de vivissecção, em que o animal é sacrificado, após intenso sofrimento. Defende o uso de recursos pedagógicos alternativos, como vídeos, simuladores, acompanhamento clínico em pacientes reais e investigações em cadáveres na prática discente.

Requer antecipação da tutela, para 'impedir a continuidade da utilização de animais vivos, independente da espécie, que resultam em dano irreversível e irreparável aos animais usados no ensino e após sacrificados'.

R. Inter. Interdisc. INTERthesis, Florianópolis, v.12, n.1, p.65-83, Jan-Jun. 2015 
A UFSM quando da sua manifestação alegou que "mesmo diante da carência de recursos, está substituindo a utilização de animais por processos modernos de aprendizagem". Ora, se a instituição assume que está, mesmo em dificuldade econômica, buscando outros processos de aprendizagens, processos modernos, por conclusão acabaram por reconhecer que os métodos tradicionais de utilização de atividades de ensino e pesquisa com animais são arcaicos. Em fundamentação da decisão liminar, assim foi disposto:

De início, deve-se salientar ser evidente que os animais merecem toda proteção do Estado, impedindo-se que sejam expostos a tratamento cruel e insensível, assegurando-lhes melhores condições de existência, vertente essa que deve sempre ser perseguida como sinal evolutivo da sociedade. A própria Constituição Federal proíbe práticas de crueldade e maus tratos a qualquer animal (art. 225, $\S 6^{\circ}$, inc. VII).

A questão de fundo traz à tona a problemática ligada à utilização de animais em atividades de pesquisa e didáticas. A questão é de difícil enfrentamento, especialmente no tocante às pesquisas acadêmicas para avanço da ciência, eis que, infelizmente, algumas ainda não podem prescindir de sua utilização. Porém, tal não autoriza que seja dispensado tratamento cruel ou maus tratos aos animais utilizados nessas experiências ou no ensino acadêmico. (grifo nosso)

E, a partir da análise legislativa e da jurisprudência das cortes superiores, decidiu a magistrada que:

Nessa toada, tenho que a utilização de animais vivos e saudáveis, de qualquer espécie, para fins didáticos, cirurgias experimentais ou fins terapêuticos, nas aulas práticas da Universidade, especialmente aqueles em que resulte na morte ou danos permanentes, constitui tratamento cruel, que deve ser impedido.

E conclui a decisão liminar,

Assim sendo, forçoso concluir que, à míngua de maiores informações circunstância a ser superada com o avançar da instrução deste feito- a Universidade deverá abster-se de utilizar animais saudáveis para fins didáticos e experimentais (incluída aí atividades de pesquisa), devendo providenciar meios alternativos nesse mister.

Em Embargos de Declaração interpostos em face da decisão que deferiu o pedido de tutela antecipada para obstar a utilização de animais saudáveis para fins de didáticos e experimentais pela requerida, assim foi julgado:

\footnotetext{
A despeito das razões expostas, não vislumbro, no caso em exame, a ocorrência das apontadas omissões, obscuridades ou contradições. Entendo, ao contrário que os pontos relevantes foram devidamente abordados na decisão, que foi fundada nos elementos constantes dos autos no momento do exame do pedido liminar.

Penso, nesse talante, que os questionamentos suscitados nestes embargos derivam, em verdade, da ausência de interpretação contextual da decisão em cotejo. Admitir-se o contrário seria presumir que a UFSM, em sua defesa, fez uso de argumentos ingênuos ou, pior, irônicos, circunstância que causaria enorme estranheza a esta Magistrada.
}

R. Inter. Interdisc. INTERthesis, Florianópolis, v.12, n.1, p.65-83, Jan-Jun. 2015 
Ou o que pensar do argumento de que, 'se ordenhada uma vaca, estaria havendo descumprimento à ordem judicial'?? Ou daquele que menciona que, se ao final de uma consulta, o animal não estiver doente (diferentemente do indicado por seu dono) estar-se-á descumprindo a determinação deste Juízo??

Ao analisar os argumentos infantis e desabonatórios da UFSM ao buscar alteração na decisão liminar de proibição de utilização de animais saudáveis para fins didáticos e experimentais na Instituição, se encaixa, com precisão, o argumento de Donaldson e Kymlicka (2013, p. 5) ao afirmarem que "quando o movimento de defesa animal começa a ameaçar os interesses econômicos, a indústria de utilização animal se mobiliza para desacreditar o movimento". A juíza de primeiro grau continua a argumentação afirmando que:

Ocorre que a presente ação tem por objeto, essencialmente, conferir proteção aos animais contra os maus tratos nas práticas de ensino e pesquisa da Universidade, independente da espécie, razão pela qual, na decisão em debate, assentei ser necessário impedir condutas dessa natureza, contra qualquer espécie animal, verbis:

'Nessa toada, tenho que a utilização de animais vivos e saudáveis, de qualquer espécie, para fins didáticos, cirurgias experimentais ou fins terapêuticos, nas aulas práticas da Universidade, especialmente aqueles em que resulte na morte ou danos permanentes, constitui tratamento cruel, que deve ser impedido.'

$[\ldots]$

ANTE O EXPOSTO, rejeito os presentes Embargos de Declaração, apenas consignando que a UFSM deve abster-se de utilizar animais saudáveis para fins didáticos e experimentais (incluídas atividades de pesquisa) na instituição, devendo providenciar meios alternativos para esse intento, nos termos da fundamentação, ou seja, quando tais práticas configurarem maus tratos, vale dizer, quando forem empregados procedimentos traumáticos e dolorosos aos animais, de qualquer espécie,não se inserindo nestas condições o manejo adequado, avaliações clínicas e o tratamento terapêutico recomendado ou necessário ao bem estar animal.

O raciocínio antropocentrista radical apresentado pelos procuradores da

UFSM não foi diferente do raciocínio apresentado pelo TRF - 4 Região ao decidir a Suspensão de Liminar n. ${ }^{\circ}$ 5019048-51.2013.404.0000/RS acerca da liminar concedida, a decisão do TRF4 opta por não seguir os novos paradigmas constitucionais e suspende a eficácia da antecipação de tutela concedida:

Com efeito, embora veja como necessária a adoção de métodos substitutivos pelo meio científico, certo é que a utilização de animais em atividades de ensino e pesquisa está devidamente regulada por lei.

De outra parte, na hipótese, não há demonstração de que a UFSM venha dispensando tratamento cruel aos animais em suas práticas de ensino, em desacordo com a Lei Arouca ou incidindo nas sanções dispostas na Lei de Crimes Ambientais.

Assim situado o tema, é possível, de fato, que a imediata proibição de a Universidade utilizar animais vivos, saudáveis, em suas atividades de pesquisa venha a acarretar prejuízos no campo científico, sobretudo em se

R. Inter. Interdisc. INTERthesis, Florianópolis, v.12, n.1, p.65-83, Jan-Jun. 2015 
considerando os projetos em curso - já contemplados com recursos financiados na ordem de mais de vinte milhões de reais -, que podem ser paralisados, inclusive, caso mantida a decisão.

A decisão só preocupou com os possíveis (alegados) prejuízos científicos, sem considerar, em nenhum momento, os prejuízos causados aos animais nãohumanos expostos aos experimentos e aos procedimentos pedagógicos. A maior preocupação se deu com possíveis perdas nas pesquisas científicas. Atualmente o processo se encontra concluso para sentença.

\section{CONSIDERAÇÕES FINAIS}

A prática de vivissecção, ou seja, a experimentação animal tanto no âmbito do ensino quanto da pesquisa não é um tema recente e nem livre de controvérsias. Felipe (2007, p. 265) salienta que desde os tempos de Descartes, que defendia a teoria dos animais autômatos (destituídos de consciência, pensamento e linguagem), a vivissecção foi moralmente legitimada e amplamente praticada pela comunidade cientifica. Conforme a autora (FELIPE, 2007, p.265): "Até o século XX, a vivissecção era realizada como espetáculo, levado a cabo em praça pública por cirurgiões circenses".

A Constituição Federal de 1988, conforme destacado, inaugurou um novo olhar sobre a questão ambiental no Brasil ao elevar o direito ao meio ambiente ecologicamente equilibrado à categoria de direito fundamental. $\mathrm{O}$ texto constitucional introduz não apenas uma dimensão social, mas também ética e econômica na relação entre os seres humanos e o ambiente, permitindo inclusive a inclusão dos animais não humanos para além da sua função ecológica ao vedar a prática de crueldade para com os mesmos.

Assim, a Constituição Federal de 1988, em seu artigo 225, paragrafo $1^{\circ}$, inciso VII, veda a prática de crueldade com os animais. Para regulamentar o referido dispositivo, no que diz respeito à experimentação animal, foi sancionada em 2008 a Lei 11.794/2008, conhecida como Lei Arouca. A Lei Arouca revogou a Lei 6.638/1979, que estabelecia normas para a prática didático-científica da vivissecção de animais.

Contudo, o embate político e jurídico em torno do uso de animais no ensino e na pesquisa, sobretudo nas Universidades brasileiras não deixou de existir. Muito 
pelo contrário, como exemplificam as Ações Civis Públicas comentadas no texto. Resta evidente a resistência das Universidades em adotar métodos alternativos mesmo diante das exigências legais.

Atualmente, de acordo com o que dispõe a Constituição Federal e a Lei dos Crimes Ambientais, o uso de métodos alternativos (quando existentes) é um imperativo, sob pena de se estar cometendo um crime ambiental. Geralmente os defensores da vivissecção sustentam que o uso de animais é justificado em razão dos ganhos sociais com o desenvolvimento de vacinas e fármacos, por exemplo, bem como os altos custos que representariam os investimentos em métodos alternativos. Estes inclusive, foram argumentos utilizados pela UFSC em sua defesa na ACP movida pelo IAA. A posição da UFSC, bem como das outras Universidades, reflete argumentos utilizados de forma geral pelos defensores da vivissecção, que gostariam fazer acreditar o público que o uso de animais em experimentos é necessário (FRANCIONE, 2013, p. 96). Tais argumentos, contudo, podem ser contestados em vários níveis. Francione (2013, p.96) aponta pelo menos cinco argumentos contrários: primeiro, o uso rotineiro de animais em procedimentos médicos ou terapias, nos faz questionar se realmente podemos atribuir tais descobertas e novidades aos testes em animais, ou seja, será que elas não poderiam ocorrer mesmo sem o uso de animais?

Segundo, afirmar que o uso animal é essencial para a saúde humana é considerar que não há outro modo de solucionar as questões de saúde humana sem utilizar animais (FRANCIONE, 2013, p.97). Para Francione (2013, p.97): "Os experimentos em animais custam bilhões de dólares anualmente. Se esses dólares fossem gastos de outras maneiras, o resultado final poderia ser melhor". E conclui: "Em vários sentidos, a escolha de usar experimentos em animais para resolver um problema é uma decisão tão politica quanto científica" (FRANCIONE, 2013, p.97).

Terceiro, nem sempre o modelo animal é adequado para mostrar dados que dizem respeito aos seres humanos, muito pelo contrario. Em muitas instâncias o uso de animais tem sido contraproducente (FRANCIONE, 2013, p.97). O quarto ponto levantado por Francione diz respeito ao uso trivial de animais em experimentos que podem ser considerados desnecessários e até mesmo bizarros. $O$ autor relata que: "na Universidade da Califórnia, por exemplo, os experimentadores amputaram os dedos de oito macacos-corujas e depois examinaram seus cérebros 
para averiguar se sua percepção havia sido alterada para levar em conta a amputação" (FRANCIONE, 2013, p. 100).

Por último, os defensores da vivissecção alegam que quando os animais são usados, os pesquisadores tentam minimizar ao máximo o sofrimento e a dor dos animais. Contudo, Francione (2013, p.104) afirma que: "Alguns vivisseccionistas não acreditam que a dor e o sofrimento possam ser medidos, e muitos acham que nem mesmo os procedimentos intensamente invasivos são dolorosos ou angustiantes para os animais".

Os casos em discussão, das três Ações Civis Públicas (ACPs) propostas recentemente, envolvendo a Universidade Federal de Santa Catarina (UFSC), a Universidade Federal de Santa Maria (UFSM) e a Universidade Estadual de Maringá (UEM) demonstram que apesar dos argumentos contrários a realização da vivissecção esta é uma prática presente, aceita e tratada com "naturalidade" pela sociedade de uma forma geral.

No entanto, se a Constituição Federal de 1988 veda a prática de crueldade para com os animais como pode a Lei Arouca regular tais práticas? Os questionamentos a respeito da constitucionalidade da Lei estão presentes desde a sua entrada em vigor. Para os juristas que atuam na defesa animal, a Lei Arouca, é considerada inconstitucional, justamente em razão da vedação da crueldade para com os animais e, portanto, a sua aplicação nos laboratórios de pesquisa (privados ou públicos) e nas salas de aula dos cursos biomédicos tem permitido a propositura de Ações Civis Públicas questionando o uso de animais na pesquisa e, sobretudo, na docência, cujos métodos alternativos são bastante desenvolvidos e conhecidos, como demonstrado nos casos da UFSC, UFSM e UEM.

Talvez, o próximo passo neste embate político e jurídico tenha que ser dado no sentido de provocar o Ministério da Educação para o estabelecimento de uma política nacional de aparelhamento das Universidades públicas com métodos alternativos à vivissecção. Assim, poderemos chegar ao banimento total de tais práticas tanto nas salas de aula, como no desenvolvimento de pesquisas.

R. Inter. Interdisc. INTERthesis, Florianópolis, v.12, n.1, p.65-83, Jan-Jun. 2015 


\title{
ANIMAL EXPERIMENTATION: A LEGAL FIGHT IN BRAZILIAN UNIVERSITIES
}

\begin{abstract}
:
Vivisection, or the use of animals in experiments, testing or education is part of a context in which many people still think represent an emergency conflict that requires the choice of human interests rather than the interests of animals. In Brazil, the 1988 Federal Constitution, in Article 225, paragraph 1, item VII, prohibits the practice of cruelty to animals. To regulate the said device, was passed in 2008 the Law 11.794 / 2008, known as Arouca Law, establishing procedures for the scientific use of animals and the Law 9.605 / 2008, which deals with environmental crimes. However, according to Brazilian Constitution, is it possible to sustain the use of animals in teaching and research, especially in universities? The aim of this paper is to analyze the Brazilian legislation regarding the use of animals in testing, teaching and research, and to discuss the observation of this legislation during the lawsuits filled in recent years by animal advocacy organizations against several Brazilian universities. The results point to a disagreement between the practices prevailing in the universities, the legislation and the Brazilian Constitution.
\end{abstract}

Keywords: Animal rights. Vivisection. Animal experimentation. Cruelty. Civil action.

\section{EXPERIMENTACIÓN ANIMAL: UNA LUCHA JURÍDICA EN LAS UNIVERSIDADES BRASILEÑAS}

\section{Resumen:}

La vivisección, o la utilización de animales en experimentos, tests o educación, forma parte de un contexto en que muchas personas todavía piensan que se trata de un conflicto de emergencia que requiere optar por los intereses humanos en lugar de los intereses de los animales. La Constitución Federal Brasileña de 1988, en el artículo 225, párrafo 1 , artículo VII, prohíbe la crueldad hacia los animales. Para regular el citado dispositivo, fue aprobada en 2008 la Ley 11.794 / 2008, conocida como Ley Arouca, que establece procedimientos para el uso científico de los animales, y la Ley 9.605 / 2008, que se ocupa de los delitos ambientales. Sin embargo, frente a lo que establece la Constitución, ¿es posible sustentar el uso de animales en la docencia y en la investigación, especialmente en las universidades? El propósito de este trabajo es analizar la legislación brasileña sobre el uso de animales en tests, en la docencia y en la investigación, y discutir la aplicación de la legislación citada en las demandas presentadas en los últimos años por las organizaciones de defensa de los animales contra varias universidades brasileñas. Los resultados indican un desacuerdo entre las prácticas que prevalecen en la universidad, la legislación y lo que dispone el texto constitucional.

Palabras-clave: Derechos de los animales. Vivisección. Experimentación con animales. Crueldad. Acción civil. 


\section{REFERÊNCIAS}

ALBUQUERQUE, Leticia. MEDEIROS, Fernanda Luiza Fontoura de. Lei Arouca: Legítima proteção ou falácia que legitima à exploração? CONPEDI; UFSC. (Org.). DIREITO AMBIENTAL II: XXIII Encontro Nacional do CONPEDI/UFSC. 1ed.FLORIANÓPOLIS: CONPEDI, 2014, v. , p. 307-336.

BENJAMIN, Antonio Herman de Vasconcelos e. O meio ambiente na Constituição Federal de 1988. In Informativo Jurídico da Biblioteca Ministro Oscar Saraiva, v.19, n.1, jan./jun. 2008.

BRÜGGER, Paula. Vivissecção: fé cega, faca amolada? In MOLINARO, Carlos Alberto; MEDEIROS, Fernanda Luiza Fontoura de; SARLET, Ingo Wolfgang; FENSTERSEIFER, Tiago (org.). A dignidade da vida e os direitos fundamentais para além dos humanos: uma discussão necessária. Belo Horizonte: Fórum, 2008, p. $145-174$.

DONALDSON, Sue; KYMLICKA, Will. Zoopolis: a political theory of animal rights. Oxford: Oxford University Press, 2013.

FEIJÓ, Anamaria Gonçalves dos Santos. Utilização de animais na investigação e docência: uma reflexão ética necessária. Porto Alegre: EDIPUCRS, 2005.

FELIPE, Sônia. Ética e experimentação animal : fundamentos abolicionistas. Florianópolis : EDUFUSC, 2007.

FRANCIONE, Gary. Introdução aos Direitos Animais. Campinas, SP: UNICAMP, 2013.

LEVAI, Laerte Fernando. Direito dos Animais. Campos do Jordão: Mantiqueira, 2004.

MEDEIROS, Fernanda Luiza Fontoura de. Direito dos Animais. Porto Alegre: Livraria do Advogado, 2013.

MEDEIROS, Fernanda Luiza Fontoura de. Meio Ambiente: direito e dever fundamental. Porto Alegre: Livraria do Advogado, 2004. 
SILVA, Vasco Pereira da. Verdes são também os direitos do homem. Cascais: Principia, 2000.

SINGER, Peter. Ética Prática. São Paulo: Martins Fontes, 2002.

Artigo:

Submetido em 11.05.2015

Aceito em 14.06.2015

R. Inter. Interdisc. INTERthesis, Florianópolis, v.12, n.1, p.65-83, Jan-Jun. 2015 